\title{
Slurs, Stereotypes and Insults
}

\section{Eleonora Orlando \& Andrés Saab}

\section{Acta Analytica}

International Periodical for Philosophy

in the Analytical Tradition

ISSN 0353-5150

Acta Anal

DOI 10.1007/s12136-020-00424-2 
Your article is protected by copyright and all rights are held exclusively by Springer Nature B.V.. This e-offprint is for personal use only and shall not be self-archived in electronic repositories. If you wish to self-archive your article, please use the accepted manuscript version for posting on your own website. You may further deposit the accepted manuscript version in any repository, provided it is only made publicly available $\mathbf{1 2}$ months after official publication or later and provided acknowledgement is given to the original source of publication and a link is inserted to the published article on Springer's website. The link must be accompanied by the following text: "The final publication is available at link.springer.com". 


\title{
Slurs, Stereotypes and Insults
}

\section{Eleonora Orlando ${ }^{1}$ (iD $\cdot$ Andrés Saab $^{1}$}

Received: 8 July 2019 / Accepted: 27 January 2020/Published online: 13 February 2020

(C) Springer Nature B.V. 2020

\begin{abstract}
This paper is about paradigmatic slurs, i.e. expressions that are prima facie associated with the expression of a contemptuous attitude concerning a group of people identified in terms of its origin or descent ('spic'), race ('nigger'), sexual orientation ('faggot'), ethnia or religion ('kike'), gender ('whore'), etc. Our purpose is twofold: (i) explaining their expressive meaning dimension in terms of a version of stereotype semantics and (ii) analysing their original and most typical uses as insults, which will be called with a neologism 'insultive', in terms of a speech act theory.
\end{abstract}

Keywords Expressive meaning $\cdot$ Slurs $\cdot$ Stereotypes $\cdot$ Speech act theory

This paper is about paradigmatic slurs, i.e., expressions that are prima facie associated with the expression of a contemptuous attitude concerning a group of people identified in terms of its origin or descent ('spic'), race ('nigger'), sexual orientation ('faggot'), ethnia or religion ('kike'), gender ('whore'), etc. ' Our purpose is twofold: (i) explaining their expressive meaning dimension in terms of a version of stereotype semantics and (ii) analysing their original and most typical uses as insults, which will be called with a neologism 'insultive', in terms of a speech act theory. Therefore, in the first section, we argue for a conception of the expressive meaning of slurs as culturally determined evaluative stereotypes. In the second section, we put forward an account of their insultive uses by appealing to some central concepts of classical pragmatics. An

\footnotetext{
${ }^{1}$ We put together what Jeshion (2013b) calls 'group-referring' ('commie', 'T-bagger', 'faggot', 'dyke') and 'personal' ('fatso', 'druggie', 'whore', 'wino', 'pimp') slurring terms because we think that there is no significant difference between them: in both cases, there is prima facie a group of people that is the target of a contemptuous attitude.
}

Eleonora Orlando

eleonoraorlando@sadaf.org.ar

Andrés Saab

al_saab75@yahoo.com.ar

1 National Research Council (CONICET), University of Buenos Aires, Bulnes 642 (1176), Buenos Aires, Argentina 
important clarification is in order: we intend to cover not all the group slurs that are in use in the different linguistic communities but just the most paradigmatic ones, which serve to entrench the well-known racist, sexist and homophobic attitudes and practices that help to keep in place unequal social structures all over the world. We then conclude that paradigmatic slurs like the ones initially mentioned are semantically linked to evaluative stereotypes and typically (but not always) used to insult people (both belonging and not belonging in the target group). ${ }^{2}$

\section{Expressive Meanings as Stereotypes}

\subsection{Dualist or Hybrid Semantics}

It is convenient to start off by making it explicit that the proposal belongs in the approach inspired by Kaplan (1999), according to which certain expressions, including some pejoratives, require a dualist or hybrid semantics, committed to the existence of two meaning dimensions: a representational or truth-conditional meaning, making a contribution to the truth-conditions of the statements in which they occur, and an expressive or use-conditional meaning, making a contribution to their expressive correctness-conditions. ${ }^{3}$ Therefore, statements containing slurs are, on the one hand, descriptively true or false and, on the other, expressively correct or incorrect, which depends not on the state of affairs they represent but on the contexts in which they are used.

In terms of an example, a slur word like 'spic' has, on the one hand, a representational meaning, the property of having a Hispanic-American origin or descent or the set of people with a Hispanic-American origin or descent, which is contributed to the truthconditions of the statements in which it occurs. In this regard, 'spic' is identical to the purely descriptive term 'Hispanic-American', its neutral counterpart, whose representational meaning is also constituted by the property of having a Hispanic-American origin or descent. Accordingly, statements of (1) and (2)

1) Diego is a spic.

and

2) Diego is Hispanic-American.

have the same truth-conditions, specified, respectively, in (3) and (4):

3) 'Diego is a spic' is true if Diego has a Hispanic-American origin or descent.

4) 'Diego is Hispanic-American' is true if Diego has a Hispanic-American origin or descent.

\footnotetext{
${ }^{2}$ Even if the slurs that appear in this paper are never used but always mentioned, we apologise in advance for the sentences chosen to exemplify their different uses, in case someone finds them offensive.

${ }^{3}$ See, for instance, the formal proposals advanced by Potts (2003, 2005), McCready (2010), Predelli (2013) and Gutzmann (2015). 
But, on the other hand, unlike 'Hispanic-American', 'spic' also has an expressive meaning, namely, it is not a purely descriptive or expressively neutral word. In the next subsection, we will develop a proposal concerning the nature of expressive meaning so that we can determine not the conditions under which the statements containing words like 'spic' are true but the set of contexts in which they are expressively correct. Our proposal is based on the notion of stereotype, which can be considered to play a special role in selecting those contexts. ${ }^{4}$

We thus defend a kind of dualist semantics that is committed to the so-called Identity Thesis, according to which (i) the representational and the expressive meaning dimensions of a slur are independent from each other and (ii) its representational dimension is equivalent to the representational dimension of its neutral counterpart. ${ }^{5}$ Even if in this paper the thesis at stake will be mostly taken for granted, it is worth mentioning that one of the main arguments in its favour is grounded on the fact that the expressive meaning of pejoratives scopes out of truth-conditional operators, namely, expressions that affect the truth-conditional content of a statement, such as negation, propositional attitude verbs, conditionalisation, etc., as shown by the following examples:

5) Diego is not a spic.

6) Carla believes that that spic is going to be fired very soon.

7) If Diego is a spic, we will have to move to a different neighbourhood.

In uttering (5) the speaker seems to underwrite the characterisation of people (even if not Diego) as spics; in any statement of (6) that characterisation projects out of the belief context and is subscribed by the speaker; and in any statement of (7), far from being conditionally expressed, that characterisation is part of what is asserted. From our perspective, the phenomenon of scoping out shows that the expressive dimension, however it is conceived of, cannot be considered to be the slur's contribution to the truth-conditional content of the corresponding statement. ${ }^{6}$

\subsection{From Cultural to Semantic Stereotypes}

As is clear, there are cultural stereotypes associated with different groups of people, such as Hispanic-Americans, African-Americans, homosexuals, Jews, women, the working class, etc. Some of them are the same across different communities, whereas some others vary according to the community at stake. Most of them can vary considerably across time; some disappear and new ones are born. Cultural stereotypes are sets of schematic, simple-minded, oversimplified and mostly false beliefs involving a prejudicial view of the corresponding groups (Nunberg 2018). They are founded on

\footnotetext{
${ }^{4}$ Other dualist proposals have conceived of the expressive dimension in different terms: a presupposition (Schlenker 2007), a conventional implicature (Potts 2003, 2005; Williamson 2009; McCready 2010; Whiting 2013), a rule of use (Jeshion 2013b), a bias (Predelli 2013) or a set of register features (Díaz Legaspe et al. 2019).

${ }^{5}$ The Identity Thesis is the core of the so-called Neutral Counterpart Theories, such as Jeshion's (2013a, 2013b), Predelli's (2013) and Whiting's (2013), among others. For objections to that thesis, see Hom (2008, 2010), Croom (2015) and Ashwell (2016). See also Díaz Legaspe (2018) for considerations in favor of restricting the thesis in the case of some kind of slurs, the so-called 'normalising' ones. For a general defence, see Caso and Lo Guercio (2016).

${ }^{6}$ See, for instance, Potts (2005), McCready (2010) and Schlenker (2007).
} 
discriminatory attitudes and practices that are deeply entrenched in a community. Now, given that among those attitudes and practices, the symbolic ones are prominent, slur words can be conventionally linked to those stereotypes. The proposal is then to derive, from the cultural stereotypes associated with some groups, semantic stereotypes linked to the corresponding slur words. More specifically, we will conceive of the expressive dimension of slurs in terms of culturally determined semantic stereotypes of a particular sort. Notice that their respective neutral counterparts, in as far as they are purely descriptive or expressively neutral terms, do not have an expressive meaning and hence no semantic stereotype will be linked to them - though prejudicial people certainly associate also with them the corresponding cultural stereotypes.

What is a semantic stereotype? As indicated by the very term, it is a stereotypical or prototypical concept, namely, a special kind of concept. To understand its nature, it is convenient to take a look at Wittgenstein's reflections on meaning, according to which a natural language term is to be defined in terms of an open list of characteristics. On the one hand, there is no single one, or definite subset of them, that needs to be present in order for something to count as a correct instance of application of the term (none of them is necessary). On the other, something may have all the characteristics in the list and yet not be a correct instance of application of the term (the set of them is not sufficient). ${ }^{7}$ There are two features that we want to emphasise: as just explained, the list does not encode a set of necessary and sufficient conditions for the application of the corresponding term, and it is an open list and hence new characteristics may become relevant in new cases. The Wittgensteinian conception of natural language meaning has given rise to the idea of stereotypical or prototypical concepts associated with natural language terms.

The semantic theory put forward by Putnam $(1970,1975)$ can be viewed as involving a restricted use of a similar notion. However, that notion has been used to explain the meaning of not all natural language terms but just a subset of them, namely, general terms for natural kinds. Moreover, the concept at stake, what Putnam called 'the stereotype', constitutes not the whole meaning but just one meaning factor: every natural kind term has a dual meaning, basically constituted by a stereotype and an extension. The stereotype is a set of typical or paradigmatic characteristics, providing a conventional, not necessarily accurate, general, approximate and simple-minded idea of something, i.e. the members (exemplars or samples) of the extension of the corresponding term, namely, the natural kind at stake. Two aspects must be pointed out. First, according to Putnam, the stereotype, in as far as it does not encode a set of necessary and sufficient conditions for applying the term to an object, does not determine the term's extension: unlike a Fregean sense and the traditional notion of intension, the stereotype is conceptually independent of the extension, which is thought to be fixed and transmitted by means of a causal mechanism. That is why it is not part of the term's contribution to the truth-conditions of the statements in which it occurs. Consequently, the stereotype can contain misinformation: the fact that a certain feature

\footnotetext{
7 The famous passage of Philosophical Investigations concerning the word 'game' is clear on this particular point: 'Consider for example the proceedings that we call 'games'. [...] Look, for example, at board-games, with their multifarious relationships. Now, pass to card-games; here you find many correspondences with the first group, but many common features drop out, and others appear. When we pass next to ball-games, much that is common is retained, but much is lost. [...] And the result of this examination is: we see a complicated network of similarities overlapping and crisscrossing: sometimes overall similarities, sometimes similarities of detail' (Wittgenstein 1953: pf. 66, pp. 31-32). As must be recalled, the notion in play is the one of family resemblance.
} 
is included in it does not imply that it is true, let alone an analytic truth, that all the individuals falling under the term have the feature in question. ${ }^{8}$ The second aspect that we want to emphasise is that Putnamian stereotypes, like Fregean senses and traditional intensions, are conventional rules to follow if one wants to be competent with the corresponding terms. In other words, they encapsulate the information and misinformation that is obligatory to acquire in order to learn the terms.

Now, we think that a notion of stereotype with the features pointed out in the previous paragraphs can be put to work to explain the expressive meaning of slurs. ${ }^{9}$ Accordingly, a slur like 'spic' can be conventionally linked to the stereotype:

\section{'spic' = ILLEGAL, WITH A SPANISH ACCENT, POOR, UNTRUSTWOR- THY, WITH ABORIGINAL FEATURES, HARD WORKER, GOOD DANC- ER, PRONE TO LAZINESS, etc. ${ }^{10}$}

A slur stereotype is a complex concept, constituted by an open set of more basic ones; some of them are central (ILLEGAL, WITH A SPANISH ACCENT, POOR, UNTRUSTWORTHY) whereas some others may be more peripheral (WITH ABORIGINAL FEATURES, HARD WORKER, GOOD DANCER). ${ }^{11}$ Each concept represents a feature of the original cultural stereotype associated with the corresponding group - notice that there may be different ways of conceptually representing a certain feature. Another remarkable aspect is that some stereotypes may encompass two concepts that are contradictory with each other, such as, HARD WORKER and PRONE TO LAZINESS: this should not be surprising, since prejudices are clearly not at all rational. Now, as before, the two semantic aspects characteristic of Putnamian stereotypes are worth being pointed out.

First, unlike Fregean senses and traditional intensions, these stereotypes do not determine the corresponding extensions. Accordingly, the fact that a concept such as ILLEGAL is included in the 'spic' stereotype does not mean that it is true, let alone an analytic truth, that all the members of the term's extension have the feature at stake, namely, that all Hispanic-Americans are illegal. Moreover, a person may not have any of the features included in the 'spic' stereotype and be Hispanic-American (some Hispanic-Americans are legal, do not have a Spanish accent when they speak English, are rich, trustworthy, do not have an aboriginal look, etc.), and, conversely, a person

\footnotetext{
${ }^{8}$ In Putnam's own terms: 'The fact that a feature (e.g. stripes) is included in the stereotype associated with a word $\mathrm{X}$ does not mean that it is an analytic truth that all Xs have that feature, not that most Xs have that feature, not that all normal Xs have that feature, not that some Xs have that feature. Three-legged tigers and albino tigers are not logically contradictory entities. Discovering that our stereotype has been based on nonnormal or unrepresentative members of a natural kind is not discovering a logical contradiction. If tigers lost their stripes they would not thereby cease to be tigers, not would butterflies necessarily cease to be butterflies if they lost their wings' (1975: 250).

${ }^{9}$ In this respect, our proposal is different from the one advanced by Croom (2011), for whom the stereotype, though conceived of along similar lines, constitutes (what we have called) the representational meaning of the slur, namely, what is contributed to the truth-conditions of the statements in which it occurs. See Sect. 1.4. for more discussion.

${ }^{10}$ As is common, we use capital letters to designate concepts.

${ }^{11}$ We do not intend to endorse any particular conception of concepts: the proposal is meant to be compatible with whatever concepts might be thought to be (mental representations, abstract entities, etc.).
} 
may have all those features and not be Hispanic-American (for instance, she can be from the Philippines).

Second, knowledge of the stereotype is linked to competence with the word: it is obligatory for a speaker to know at least some concepts in the corresponding list to be competent with the slur. But, in as far as it is an open list, every speaker might grasp a different subset of concepts. As a matter of fact, most competent speakers will tend to agree on the central features, but different speakers may grasp different aspects or parts of the stereotype: apprehending the entire stereotype is not a requirement for competence (which, on the other hand, would be impossible since it is constituted by an open list). ${ }^{12}$ Moreover, knowing the stereotype does not imply believing that all the individuals in the term's extension have the features included in the stereotype: it only implies knowing that the slur is conventionally linked to the corresponding concepts.

In connection with the last point, it is thus worth pointing out that, as much as it happens with natural kind terms, a speaker who is competent with a certain slur (namely, she is able to associate with it a subset of the corresponding stereotypical concepts) might be ignorant or mistaken about its extension. In terms of the previous example, a speaker who competently uses 'spic' in connection with being illegal, having a Spanish accent, being poor, untrustworthy, etc. might not know exactly which property it represents or mistakenly believe that the term applies to Puerto Ricans and Mexicans but not to Chileans. In contrast, in the case of 'Hispanic-American', its neutral counterpart, a competent speaker needs to know that it applies to people of a Hispanic-American origin or descent, namely, a group that includes Chileans, as well as Puerto Ricans and Mexicans. Whereas slurs are similar to natural kind terms in this respect, their purely descriptive counterparts seem to be typical descriptive general terms, namely, terms whose use is governed by a certain description (they are both descriptively introduced and transmitted).

\subsection{Evaluative Stereotypes}

There is an aspect in which slur stereotypes are different from natural kind terms ones: not all its constitutive concepts are descriptive ones. Whereas some of them are purely descriptive, there are others that are both descriptive and evaluative, namely, they are mixed or thick, and others are purely evaluative. ${ }^{13}$ The 'spic' stereotype partially manifests this variety: whereas WITH A SPANISH ACCENT and WITH ABORIGINAL FEATURES are descriptive concepts, UNTRUSTWORTHY and ILLEGAL are thick ones, both descriptive and evaluative. Thick concepts, in particular, thick ethical concepts, such as CRUEL, COWARD and BRUTAL, have played a central role in contemporary meta-ethics; in general, they have been thought not only to describe an aspect of the world but also to guide our action. ${ }^{14}$ Without intending to go deep into the

\footnotetext{
12 According to the centrality of the concepts being grasped, it might be possible to establish different degrees of competence. As an example, a speaker who, in relation to 'spic', only grasped HARD WORKER and GOOD DANCER might be said to be less competent with the word than another one who grasped the most central concepts. This is similar to the phenomenon that Burge (1979) has called 'partial understanding'.

${ }^{13}$ For instance, UGLY and its opposite BEAUTIFUL are purely evaluative concepts that might be part of (different) slur stereotypes.

${ }^{14}$ For the distinction and its role in ethics, see Williams (1985: chapter 8). For more on thick concepts, see Väyrynen (2011).
} 
meta-ethical debate, we will consider that a thick concept not only represents a property but also encodes a global value (positive or negative), such that the possession of that property by an individual will be systematically evaluated accordingly (in a positive or negative way, respectively); following the meta-ethical debate, we will call that encoded global value 'valence'. ${ }^{15}$ In terms of some examples, COURAGEOUS applies to a person who is considered to take reasonable risks to the benefit of other people, thereby giving rise to a general situation that is viewed as morally better than the previous one, and has a positive valence; UNTRUSTWORTHY, a thick concept included in the 'spic' stereotype, applies to a person who is not worthy of being trusted, and has a negative valence. ${ }^{16}$

Now, independently of the particular valences possessed by its constitutive concepts, a slur stereotype has its own negative valence. That valence is not thus determined by (the valences of) its constitutive concepts but by the fact that the group it targets is considered to have an inferior status, on grounds of the existence of well-entrenched discriminatory attitudes. That is why each feature of the semantic stereotype, even the purely descriptive ones (such as, in our previous example, WITH A SPANISH ACCENT or WITH ABORIGINAL FEATURES), turns out to be regarded as a trace or indicator of the inferior status in question. The negative valence of a slur semantic stereotype is the product of the cultural stereotype from which it derived, which is in turn grounded on socially established practices of discrimination and, in most cases, of marginalisation and caricaturisation.

There are two aspects that we want to point out: one is a semantic aspect; the other is related to the political connotation of slurs. With regard to the first, the negative valence of a slur stereotype is an evaluative component that is thus independent of any individual attitude or action; as mentioned above, it means that the average competent speaker will tend to evaluate the members of the target group accordingly, namely, in a negative way, due to the discriminatory practices that are well-entrenched in her community. This seems to accord well with one of Hom's adequacy conditions for a successful explanatory account of slurs, namely, Derogatory Autonomy, according to which 'the derogatory force for any epithet is independent of the attitudes of any of its particular speakers' (2008: 426). As for the second aspect, in as far as the underlying discriminatory practices help determine and keep in place an unequal social structure, slurs like 'spic', 'faggot', 'kike', etc., namely, the most paradigmatic ones, have a clear political significance. It is worth pointing out that some examples, like 'nazi', 'fascist',

\footnotetext{
15 The debate has opposed cognitivists (McDowell 1981; Kirchin 2017, among others) and non-cognitivists (such as Gibbard 1992 and Blackburn 1992).

${ }^{16}$ At this point, it may be worth making the following clarification point. On the one hand, purely descriptive terms ('Hispanic-American') have only a representational meaning (an intension and/or an extension); on the other, mixed terms ('spic') have both a representational and an expressive meaning (a stereotype). But that expressive meaning is constituted by different kinds of concepts, namely, purely descriptive concepts (WITH A SPANISH ACCENT), thick concepts (ILLEGAL) and purely evaluative ones (UGLY). Therefore, the mixed term 'spic' has (i) a representational meaning, that is, it represents the property of having a Hispanic-American origin or descent (intension), and it applies to the set of Hispanic-Americans (extension), and (ii) an expressive meaning, namely, it expresses an evaluative stereotype; this one is in turn constituted by an open list of concepts, some of which are purely descriptive concepts (WITH A SPANISH ACCENT, namely, it represents the property of speaking English with a Spanish accent), whereas others are mixed or thick concepts (ILLEGAL, which not only represents the property of not being authorised to live or work in a certain country but also encodes a negative global value).
} 
'commie', etc., have a more direct political import, coming from the rejection of groups representing certain political ideologies. As is clear, these are cases in which the discrimination involved is not contributing to the existence of an unequal social structure in the above-mentioned sense. The case of slurs for dominant groups, such as 'honky' and 'cracker', is more complicated: the discrimination seems to be based on a retaliative and compensatory attitude.

Summarising, we propose to construe the expressive meaning of a slur in terms of $a$ culturally determined, evaluative stereotype; more specifically, the stereotype characteristic of a slur has a mixed, cognitive-evaluative component (a set of different kinds of concepts, most of which are thick concepts) and a purely evaluative component (a negative valence). Accordingly, in terms of our previous example, apprehending the 'spic' stereotype implies knowing not only that 'spic' is linked to certain concepts in an open list but also that it has a negative valence. In general, being competent with paradigmatic slurs amounts then to being able to associate each of them with an open list of concepts, centrally including thick ones, with a negative global value.

At the beginning of this essay, we defined the expressive meaning of a word in terms of its contribution to the expressive correctness conditions of the statements in which it occurs, namely, the set of contexts in which those statements turn out to be expressively correct. We are then in a position to specify the expressive correctness condition of (1) as follows:

8) 'Diego is a spic' is expressively correct if it is uttered in those contexts in which a cultural stereotype associated with Hispanic-Americans, epitomised in the 'spic' semantic stereotype, is in force.

It follows from this that uttering (1) in a context in which the above-mentioned cultural stereotype does not exist will turn out to be expressively incorrect. As must be clear, the notion of expressive correctness does not involve correctness in any moral sense of the word, since the contexts in which cultural stereotypes like the previous one are in force are morally reprehensible ones; in other words, there are no contexts in which uttering a sentence containing a paradigmatic slur can be considered to be morally correct (although we think that the different kinds of uses of those terms that will be distinguished below involve different degrees of moral corruption). ${ }^{17}$ In sum, from a semantic point of view, there is an expressive constituent to any slur, namely, the corresponding stereotype. Now, the utterance of a sentence containing that kind of word will be paradigmatically, though, as we will see below, not always, accompanied by an individual negative attitude. But before getting into the pragmatic details of use, we will briefly consider whether our approach is affected by some criticisms that have been advanced against other stereotype views.

\footnotetext{
${ }^{17}$ On the other hand, the above-emphasised independence between the representational and the expressive components of slurs implies that sentences such as "My dog is a spic", "That banana is a spic", "St. Paul's Cathedral is a spic" and "The square root of 606 is a spic" would turn out to be expressively correct if uttered in a context in which the 'spic' stereotype is in force. Of course, they would also be not only false but absurd (categorial mistakes). We think this does not involve any problem, since the expressive correctness (or lack of it) of absurd statements is an idle point.
} 


\subsection{On Alternative Stereotype Views}

Both Hom $(2008,2010,2012)$ and Croom $(2011,2013,2014,2015)$ have put the notion of stereotype at the core of their respective accounts of slurs. In this subsection, we will point out some differences between those conceptions and the one hereby defended to make it manifest that our proposal is not open to some criticisms aimed at them. ${ }^{18}$ First, from Hom's perspective, a stereotype is constituted by a very precise list of characteristics that amount to necessary and sufficient conditions for an individual to belong in the extension of the slur:

For example, the epithet 'chink' expresses a complex, socially constructed property like: ought to be subject to higher college admissions standards, and ought to be subject to exclusion from advancement to managerial positions, and ... because of being slanty-eyed, and devious, and good-at-laundering, and ..., all because of being Chinese. (Hom 2008: 431)

Yet, according to our previous definition, (i) a stereotype does not have such a rich and precise content (it is constituted by an open list of concepts involving a general, approximate, simple-minded and inaccurate way of characterising the 'normal' members of a group of people) and (ii) it does not encode necessary and sufficient conditions for an individual to belong in the extension of the term. Consequently, apprehending the 'chink' stereotype does not imply believing that all, most, normal or even some Chinese have any of the above-mentioned features. Moreover, neither is grasping each concept an individually necessary condition nor is grasping the set of them a jointly sufficient condition for the correct application of the term; therefore, a sentence like (9)

9) All chinks are good at laundering.

is not taken to involve either an analytic or any other kind of truth: it not only is not analytically true but also plainly false.

Consequently, our account is not open to the kind of criticisms of stereotype views advanced by Jeshion (2013a) and Technau (2016), which are synthesised in the following fragment:

Even if a speaker does not know about higher rates of college admission for Chinese students, he can still be counted as a competent speaker who knows the full meaning of 'chink'. But if he does not know that the word pejoratively refers to Chinese, he is clearly lacking its (full) meaning. (Technau 2016: 198)

As must be already clear, our proposal does not imply that being competent with 'chink' requires knowing that Chinese students have higher rates of college admissions or, for that matter, any other particular feature included in the stereotype: as explained

\footnotetext{
${ }^{18}$ We would like to thank an anonymous referee for emphasising the need of making those contrasts explicit.
} 
above, a competent speaker only needs to apprehend some part of the stereotype together with its negative valence. On the other hand, on the basis of the previous considerations, we do claim that the competent speaker may be ignorant or mistaken about the term's extension, for instance, she may think that 'chink' applies to all people having an oriental origin or descent - though, as a consequence of her grasping its negative valence, she should acknowledge that it involves a negative evaluation of the people referred to. ${ }^{19}$

Secondly, let us consider Croom's interesting account in order to emphasise another difference between our proposal and other stereotype views. As already mentioned, Croom $(2011,2013,2014,2015)$ has presented a stereotype view, which, like our own, takes on board the notion of family resemblance: more specifically, he suggests that a slur can be usefully understood as a family resemblance (rather than classical) concept consisting in a constellation of prototypical attributes. Those features should be considered as rank-ordered based on the relative degree in which their attribution to a certain target is taken as a salient indicator of concept membership, and this rank-order can be reorganised in a context-dependent manner (in practice, more or less features could be involved in a given cognitive or communicative context). In his own words:

Note also that, although speakers may typically apply the slur 'nigger' to targets attributed the highest-ranking $\left(a_{1}\right)$ as well as the greatest quantity $\left(a_{1}-a_{10}\right)$ of attributes in $\mathrm{N}$, my family resemblance account maintains (contrary to classical accounts) that speakers may still informatively or effectively apply that slur to $x$ even if that $x$ fails to possess the highest-ranking $\left(a_{1}\right)$ or even the most $\left(a_{1}-a_{10}\right)$ attributes in $\mathrm{N}$ insofar as that is the most relevant and apt lexical choice for their purpose in a particular cognitive or communicative context. (2015:35)

Therefore, for Croom, what we have called 'the representational meaning of a slur' is constituted by a contextually selected list of stereotypical attributes, none of which is a necessary condition for the application of the slur in a particular case. Although the context-dependent character of the set of stereotypical features makes the proposal immune to the above-mentioned criticisms, we think that it is more convenient to conceive of that set as an expressive meaning, independent of the truth-conditional one, on grounds of the fact that it is not affected by truth-conditional operators (it scopes out of them), as shown by the examples introduced in Sect. 1.1. As pointed out before, from our perspective, the phenomenon of scoping out shows that the stereotype

\footnotetext{
${ }^{19}$ The stereotype account rejected by Saka (2007) seems to be of the same kind: 'It has been suggested that pejoratives apply to those and only those who conform to suitable stereotype (personal communications from Alistair Isaac, Steven Todd, and Evan Dukofsky). Under this view, "Hitler was a kraut" would be true because Hitler was authoritarian, an Aryan supremacist, and bent on conquest, while "Einstein was a kraut" would be false' (2007: 125). But, as we explained above, from our perspective, the 'kraut' stereotype is part not of the representational or truth-conditional content but of the expressive content of statements containing the term, and, hence, it involves neither a necessary nor a sufficient condition for their truth or falsity.
} 
dimension cannot be considered to be the slur's contribution to the truthconditional content of the corresponding statements, as claimed by Croom. ${ }^{20}$

Now, Croom (2015) has argued against the Identity Thesis, namely, the idea that slurs and (what he calls) descriptors are co-referential expressions with exactly the same extension, on the basis of evidence of uses of slurs like the following:

\section{0) Some but not all Hispanic-Americans are spics,}

which are intuitively evaluated as true, whereas, on the assumption that the Identity Thesis holds, they must be considered to be not only false but also self-contradictory. ${ }^{21}$ As is known, Grice (1975) considers that a natural language statement can, in a certain context, serve to communicate a content that is different from its semantic content, namely, a pragmatic one. The latter, characterised as a conversational implicature, can be derived from the former together with the presumption that the Cooperative Principle is being respected, some background knowledge, and the fact that all these things are known by both the speaker and the interpreter (a mutual knowledge assumption). Now, based on this theory, we think that any instance of (10) should be interpreted as semantically expressing a literal falsehood (more specifically, a self-contradiction) but pragmatically communicating a conversationally implicated content that is true, to the effect that some but not all Hispanic-Americans have the features represented in the 'spic' stereotype, namely, not all of them are illegal, with a Spanish accent, poor, untrustworthy, with aboriginal features, etc. Schematically, such a statement has two contents:

- a semantically expressed content (some but not all Hispanic-Americans are spics) ${ }^{22}$

- a pragmatically communicated content (some but not all Hispanic-Americans are illegal, with a Spanish accent, poor, untrustworthy, with aboriginal features, etc.)

The content in (ii) is derived from the content in (i) by the flouting of the First Maxim of Quality: what the speaker semantically expresses is literally false, but in doing so, she pragmatically communicates or conversationally implicates something that is clearly true. As pointed out before, a person may not have any of the features included in the 'spic' stereotype and be Hispanic-American (some Hispanic-Americans are legal, do not speak English with a Spanish accent, are rich, trustworthy, do not have an aboriginal look, etc.) and, conversely, a person may have all those features and not be Hispanic-American (for instance, she can be from the Philippines). (In Sect. 2, we will

\footnotetext{
${ }^{20}$ In this respect, our proposal is more akin to the one presented in Camp (2013), according to which stereotypes are also constitutive of a non-truth-conditional meaning dimension. Our notion of stereotype is, however, much more directly inspired in Wittgenstein's reflections on meaning and Putnam's conception of natural kind stereotypes.

${ }^{21}$ This final paragraph has been included in attention to a useful suggestion of an anonymous referee.

${ }^{22}$ Angular brackets are conventionally used to designate propositions or propositional contents; in fact, some people would say that there are two propositions in play, a truth-conditional and a use-conditional one (see, for instance, Gutzmann 2015). As in the present essay, we do not model expressive meanings in terms of propositions; we will not say anything more specific on this point.
} 
expand on the application of the notion of conversational implicature to the account of some uses of slurs; see, in particular, Sect. 2.4. $)^{23}$

\section{The Pragmatic Dimension of Slurs}

\subsection{The Different Kinds of Uses}

Any use of a slur involves endorsing the cultural stereotype epitomised in its semantic stereotype or, in other words, taking on board the attitudes and practices of discrimination that help to keep in place an unequal social structure. Using a slur is thus making a speech act that has political significance, the same one carried by the slur words themselves. Now, as is clear, there are different kinds of uses. Their original and paradigmatic uses involve an active endorsement of the stereotype, characterised by the presence of an attitude on the speaker's part or, more specifically, a derogatory intention, namely, the intention to express, by means of using a certain sentence, an emotion of contempt. Those are acts of insulting someone, which will be characterised as involving a special illocutionary force called, with a neologism, 'insultive'. In as far as insultive acts are performed with the intention to express an emotion, they are a subkind of the more general kind of expressive speech acts. ${ }^{24}$

It is worth taking into account that, on the one hand, insultive acts can be performed by using not only slurs but also other kinds of pejoratives, as exemplified in (11) with the epithet 'stupid':

11) That stupid man has completely misunderstood the order.

It is also possible to perform an insultive act by using purely descriptive sentences, such as

12) I do not think that Hispanic-American will get the job,

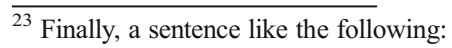

i. Diego is Hispanic-American but he is not a spic.

could also be thought to be self-contradictory, on the assumption that the Identity Thesis is in play. From our perspective, though, (i) can be interpreted in two alternative ways. One interpretation follows the lines of the interpretation proposed for (10): although (i) is literally false (self-contradictory), it conveys the true content that Diego is Hispanic-American but does not have the features represented in the 'spic' stereotype. The other interpretation takes the negation contained in (i) to be metalinguistic: what is negated is that Diego should be called 'a spic', as shown but its more natural reformulation:

ii. Diego is not 'a spic', he is Hispanic-American.

in parallel to

iii. This is not a 'bunny', this is a rabbit.

${ }^{24}$ For the classic taxonomies of speech acts, see Austin (1962) and Searle (1969). 
with a concomitant contemptuous gesture or tone. As is known, there are certain prosodic elements (voice pitch, pitch variation, intonation contour, duration of prosodic units and the manner of stress realisation, etc.) that usually indicate contempt (Sendlmeier et al. 2016).

On the other hand, it is also possible to use slurs without having a derogatory intention, that is, to make a non-insultive use of slurs. This can be exemplified by those uses in which the speaker is endorsing the stereotype in a passive way, as in uttering

13) That old couple of kikes leaving next door are adorable: they always let me use their beautiful piano. ${ }^{25}$

Moreover, in the so-called 'appropriated' or 'in-group' uses, in which slurs are used by the very members of the target group, it is not even clear that there is a genuine endorsement of the stereotype, as exemplified by an African-American who utters (14) while talking to another African-American:

\section{4) You are my nigga,}

The speaker may be either (i) merely pretending to endorse it or (ii) endorsing it with the purpose of reversing its negative valence by adopting a new political and, fundamentally, moral perspective. For instance, in the case of 'spic', some features, like WITH A SPANISH ACCENT, may start being regarded as something valuable rather than being the trace or indicator of an inferior status.

Given the scope of this essay, in this second section, our analysis will be focused on insultive acts performed by using slurs; namely, the analysis will be restricted to a certain subkind of insultive acts (which, as previously mentioned, are in turn a subkind of expressive acts). Their purpose is expressing contempt for the corresponding target groups. Their analysis will thus reveal a new, pragmatic expressive factor, the derogatory intention, which combines with the semantic expressive factor, the stereotype, described in the first part of this essay. Therefore, in this second section, we will offer two arguments for the thesis that there is a special kind of illocutionary force (insultive) that is characteristic of those uses. The first one, inspired in Searle's (1969) speech act theory, is based on a general analogy between the kinds of speech acts he has identified and the hereby proposed insultive acts. The second one, inspired in some ideas put forward by Strawson (1964), shows that the derogatory intention, or intention to express contempt for the target group, is a kind of communicative intention and, as such, can be considered to be indicative of a specific illocutionary force. ${ }^{26}$

\footnotetext{
25 These correspond to what Jeshion (2013b) calls 'non-weapon uses'. The examples are also similar to the ones mentioned by Camp (2013: 332-333). See, for example, the following paragraph from Technau: 'The success of a non-pejorative use is not always dependent on the speaker's group membership, it is always dependent, however, on the speaker's friendly bonds with his audience and the hearers' knowledge of his friendly intentions and attitudes' (2018: 36).

${ }^{26}$ The account that follows have some points of contact with Liu's (2018) Force Indicator account, according to which slur words are derogatory because they are illocutionary force indicators for derogation. However, as will be clear below, there are many differences between both accounts, given, among other aspects, that Liu's account (i) does not include stereotypes and (ii) does not define the illocutionary force characteristic of (what we call) insultive uses in terms of the presence of a derogatory communicative intention along Gricean lines.
} 


\subsection{The Derogatory Intention as an Essential Condition for Insultive Acts}

As is known, on his account of speech acts, Searle has tried to identify an essential condition for each kind of act or illocutionary force. In relation to promises, he proposes the following one:

$S$ intends that the utterance of $T$ will place him under an obligation to do A. The essential feature of a promise is that it is the undertaking of an obligation to perform a certain act. [...] It is clear, however, that having this intention is a necessary condition of making a promise, for if a speaker can demonstrate that he did not have this intention in a given utterance he can prove that the utterance is not a promise.[...] (1969: 60) $)^{27}$

Along these lines, we want to propose the following essential condition for our subkind of insultive acts:

15) Given a speaker $S$, a sentence $t$ containing a slur ' $g$ ' and a hearer $H$, in uttering $t S$ insults $H$ if and only if $S$ intends that the utterance of $t$ expresses her contempt for the group $G$ (namely, $S$ intends that the utterance of $t$ expresses her active endorsement of the semantic stereotype of ' $\mathrm{g}$ ').

As it happens in the case of promises, there is a speaker's intention playing a central role, but this time it is her intention to use the sentence as a means to express contempt for a certain group. Being contempt a complex emotional attitude, our hypothesis is that it has at least three different components: (i) a doxastic one, namely, the belief that the members of the target group have certain stereotypical features; (ii) an evaluative one, that is, a negative global evaluation of them (that is, the active endorsement of the stereotype's negative valence); and (iii) an affective one, namely, a negative feeling towards all the members in the group. That is why we have characterised this intention as a derogatory intention.

An important clarification is in order: there are two basic kinds of cases. First, those cases in which the insult is intended for the hearer: in these cases, the hearer is classified as belonging in the target group, as exemplified by a use of

16) You are a spic: that is why you have not been invited to my party. ${ }^{28}$

But there are also cases, as our initial (1), repeated below for the sake of clarity,

1) Diego is a spic,

in which the insult is intended for a third person, namely, in these cases it is Diego and not the hearer who is classified by the speaker as belonging in the target group. In this second kind of case, we will say that, in contrast with the third person in question,

\footnotetext{
${ }^{27}$ From this, he derives what he calls 'the essential rule', according to which 'the utterance of $\operatorname{Pr}$ counts as the undertaking of an obligation to do A' (1969: 63).

${ }^{28}$ Notice that the speaker may be making a mistake, namely, she may take the hearer to belong in the target group even if that is not the case. In other terms, the first part of the statement ("You are a spic") may be false.
} 
the hearer himself is not being insulted, though he may well get offended - for instance, if that third person is a close friend of his, or if he is sensitive to the prejudicial view underlying any use of a slur. ${ }^{29}$

Accordingly, it is possible to specify the condition for an expressively correct insultive use of (1) in the following terms:

17) 'Diego is a spic' is an expressively correct insult if and only if it is uttered in those contexts in which (i) the cultural stereotype associated with Hispanic-Americans, epitomised in the 'spic' semantic stereotype, is in force and (ii) the speaker has a derogatory intention concerning Hispanic-Americans.

In other words, for the statement to be specifically an expressively correct insult, the essential condition for insults must be met: not only the cultural stereotype associated with Hispanic-Americans, epitomised in the 'spic' semantic one, must be in force (which is, as stated before, the condition for the expressive correctness of any use of a sentence containing 'spic'), but also the speaker must have a derogatory intention concerning Hispanic-Americans (which is a condition for the expressive correctness of insultive uses in particular). The only difference between a between (1) and (16) is that in uttering (1) with a derogatory intention, the insult is intended for a third person, who is classified as belonging in the corresponding target group, whereas in uttering (16), it is intended for the hearer or interlocutor, and it is him who is classified as belonging in the group at stake.

Now, which ones would be force indicating devices in the case of our subkind of insultive acts? They are elements not of the propositional content of the statement but of what can be characterised as its evaluative charge: the statement has a negative evaluative charge determined by the speaker's active endorsement of the corresponding stereotype's negative valence. As we said before, a slur stereotype has a negative valence; in insultive uses, the speaker actively endorses it by adopting an evaluative attitude of the same, negative sign, which is, as we have seen, part of what is involved in her intention to express contempt for the group at stake. In terms of the previous example, an insultive use of (1) has not only a truth-value (it is true if as a matter of fact Diego has a Hispanic-American origin or descent) but also a negative evaluative charge, given that the speaker is actively endorsing, by adopting a negative evaluative attitude towards Hispanic-Americans, the negative valence of the 'spic' stereotype. Evaluative charge is to the expressive meaning dimension what truth-value is to the representational one (therefore, on the one hand, if the statement's truth-condition is satisfied, it will turn out to be true; on the other, if the expressive correctness condition for insultive uses is satisfied, it will turn out to be negatively charged).

In connection with this, it is worth recalling something Searle has pointed out concerning promises:

It is possible to perform the act without invoking an explicit illocutionary forceindicating device where the context and the utterance make it clear that the essential condition is satisfied. I may say only "I'll do it for you", but the

\footnotetext{
${ }^{29}$ In the following subsection, we will expand on the difference between insulting and offending.
} 
utterance will count as and will be taken as a promise in any context where it is obvious that in saying it I am accepting (or undertaking, etc.) an obligation. Seldom, in fact, does one actually need to say the explicit "I promise". (1969: 68, our emphasis)

Likewise, an utterance of a purely descriptive sentence like (12), repeated below,

12) I do not think that Hispanic-American will get the job,

will count as an insult in any context in which it is obvious, by the concomitant presence of a contemptuous tone or gesture, that in uttering that sentence the speaker is satisfying what we have considered to be the essential condition for an insultive act of this kind, namely, she intends her statement to express her contempt for the group at stake, namely, she intends it to express her active endorsement of the cultural stereotype for that group, though, one that is not epitomised in any semantic stereotype, since 'Hispanic-American', being a purely descriptive term, does not have an expressive meaning. In these cases, the negative evaluative charge of the statement is determined not by the speaker's active endorsement of a semantic factor (the stereotype's negative valence) but by her concomitant contemptuous tone or gesture.

\subsection{Derogatory Intentions as Communicative Intentions}

As previously announced, we will apply some ideas advanced by Strawson (1964) to show that an insultive act, as any complex speech act, involves many communicative intentions, being the derogatory intention the most important one. The analysis will thus reveal that a derogatory intention, regarded as essential to an insultive act, is a communicative intention in the Gricean sense (Grice 1957) and, hence, the act at stake can be taken to exemplify a kind of illocutionary act. Finally, we will oppose the illocutionary act of insulting to the perlocutionary act of offending, in a parallel with Strawson's distinction between the illocutionary act of warning and the perlocutionary act of impressing. Notice then that derogatory intentions, being a kind of communicative intention, are not private and purely individualistic mental states, of which insultive acts would be mere verbal expressions: in contrast, they are speakers' intentions to produce in their hearers some mental states by means of the hearers' recognition of those very intentions. According to what we have argued so far, a speaker uses a sentence containing a slur (or, for that matter, its neutral counterpart) with a derogatory intention if she has the intention to (use it to) express her contempt for the associated group. If this is so, she must also thereby intend the hearer to grasp that contempt. Our contention is that, as much as it happens with Gricean communicative intentions, she will also have the intention that her first intention be recognised by the hearer and, more importantly, that it be the hearer's recognition of that intention the reason for its accomplishment (namely, for the hearer to grasp her contempt).

The following quote from Strawson's text will play a central role in arguing for the three above-mentioned points:

[...] in the case where I do not simply inform, but warn, you that $p$, among the intentions I intend you to recognise (and intend you to recognise as intended to be recognised) are not only the intention to secure your belief that $p$, but the 
intention to secure that you are on your guard against $p$-perils. The difference (one of the differences) between showing off and warning is that your recognition of my intention to put you on your guard may well contribute to putting you on your guard, whereas your recognition of my intention to impress you is not likely to contribute to my impressing you (or not in the way I intended). (1964: 453)

First of all, as is clear from the quote, warning is a complex speech act: there is more than one effect that the speaker intends to achieve, in particular, more than one mental state that the speaker has the intention to produce in the hearer. In uttering, for instance,

18) I see a fire in the building next door,

on the one hand, the speaker intends to inform the hearer about a certain situation in the world, namely, to produce in him the belief that the world is a certain way, in particular, that there is a fire nearby. On the other hand, she intends to warn him about some danger; namely, to produce in him the intention to be on his guard or go to a safe place. One may think that there are two illocutionary acts involved, an act of asserting something and an act of warning someone: in asserting that she sees a fire, the speaker is warning the hearer about a dangerous situation. At this point, it is possible to wonder whether there are really two different acts or rather one act that is described in two alternative ways; namely, from an ontological point of view, it is not clear how many entities (actions or events) we are dealing with. Without intending to go deep into this ontological problem, we will only point out, in the first place, that it is a general problem, that is, not a problem that affects only speech acts. As acknowledged by Davidson (1980), the problem is ubiquitous: when someone turns on the light and thereby alerts a burglar hidden in the garden, is she performing two different actions or just one that can be described in different ways? Secondly, since the intention to warn the hearer is more important than the intention to inform him, we will suggest that the speech act of warning is implemented or realised by a more basic assertive speech act so that the act is more accurately described not as an assertion but as a warning. (As much as there are different layers of properties, we might think that there are different layers of speech acts.)

Now, from our perspective, in insulting, as much as in warning, there is an additional effect that the speaker intends to achieve: here too, she is looking for a complex primary response. Coming back to one of the previous examples, repeated below, in uttering

16) You are a spic: that's why you have not been invited to my party,

on the one hand, the speaker intends to inform the hearer about a certain situation in the world, namely, to produce in him the belief that he belongs in the group of stereotypically characterised and negatively evaluated Hispanic-Americans (a nonneutral or expressively loaded classificatory intention). On the other hand, she intends to express her contempt for the group at stake, namely, she intends him to grasp her emotional attitude concerning that group (her derogatory intention). Once again, one may think that there are two illocutionary acts involved, an act of asserting something and an act of insulting someone: in asserting that the hearer is a spic, the speaker is insulting him. As before, since the derogatory intention is more important than the informative one, we will suggest that the speech act of insulting is implemented or 
realised by a more basic assertive speech act so that the act is more accurately described not as an assertion but as an insult. ${ }^{3031}$

Second, as we have seen, the two intentions involved in the warning case are two communicative intentions in the Gricean sense: the two mental states that the speaker intends to produce in the hearer are intended to be produced by means of his recognition of her intention. As stated by Strawson, the act of warning, like the basic act of asserting in which it is usually implemented, achieves its effect by means of a Gricean mechanism, namely, the hearer is warned about something because he recognises the speaker's intention to warn him about it; in that respect, it can be contrasted with the act of showing off, which does not achieve its effect in the same way, namely, the hearer does not get impressed because he recognises the speaker's intention to impress him.

Likewise, we think that the insult case also involves two communicative intentions in the Gricean sense: the two mental states that the speaker intends to produce in the hearer are intended to be produced by means of his recognition of her intention. The act of insulting, like the basic act of asserting/ordering/asking in which it is usually implemented, achieves its effect by means of a Gricean mechanism; in that respect, it is like warning and unlike impressing. As before mentioned, in insulting someone, the speaker intends not only that her addressee recognises her intending him to believe that he belongs in a certain group of people stereotypically characterised (her expressively loaded classificatory intention) but also that he recognises her intending him to grasp her contempt for that group (namely, her derogatory intention). Now, it is the hearer's recognition of this last intention what determines its success, namely, he is grasping the speaker's contempt. Schematically, given a speaker $S$, a hearer $H$ and a group slur ' $\mathrm{g}$ ', when $S$ insults $H$ (or a third person) by using ' $\mathrm{g}$ ', there are certain conditions that are met:

- $S$ intends that $H$ grasps her contempt for the group of people to which ' $\mathrm{g}$ ' applies.

- $S$ intends that $H$ recognises the intention specified in (i).

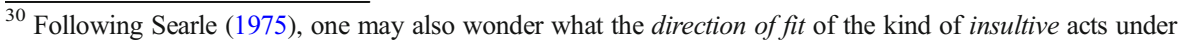
study could be; more specifically, for instance, whether in that subkind of insultive acts the propositional content adjusts to the world (descending force, characteristic of assertive speech acts) or, on the contrary, the world adjusts to the propositional content (ascending force, characteristic of directive speech acts). The concept of direction of fit alludes to the relation between the propositional content of a statement and a fact in the world. Therefore, when the propositional content does not adjust to a world fact or vice versa, as is the case with expressive speech acts, Searle takes the direction of fit to be empty or null. Now, as we have seen, our insultive acts introduce a different kind of expressive dimension, which is not at all representational, constituted by what we have called 'their negative evaluative charge'. We will then claim that they inherit the direction of fit of the other, more basic illocutionary force being involved: if it is an assertion, as in (1) and (19) above, the direction of fit will be descending; if, on the contrary, the insultive act involves a sentence such as "You, spics, form a separate line to be interrogated!", it will be ascending, as it happens with orders and promises.

${ }^{31}$ This proposal is different from Tenchini and Frigerio's (2016), since they seem to think that there are two different speech acts that are correlated with two different truth-conditional propositions expressed by the corresponding sentence. We do not agree: there is only one truth-conditional proposition, as in the warning case. But there are expressive aspects of that proposition that determine the presence of an insultive act. An alternative would be thinking that those expressive aspects give rise to an independent, use-conditional proposition (as in Gutzman 2015).
} 
- $S$ intends that it should be $H$ 's recognition of her intention (i) what gives $H$ a reason to grasp her contempt. ${ }^{32}$

As must be clear, (i), (ii) and (iii) constitute the Gricean conditions for an intention to be a communicative intention: a derogatory intention is thus a kind of communicative intention.

Now, it is interesting to take into account what is involved in the speaker's derogatory intention and what the resulting mental state of grasping the speaker's contempt amounts to. The derogatory intention is S's intention that H forms a complex mental state constituted by different components, correlated with the previously mentioned ones constituting the emotion of contempt:

(i) the (second-order) belief that $S$ believes that the members of the target group have certain stereotypical features (a doxastic component)

(ii) the acknowledgement that $S$ evaluates them negatively, i.e., in accordance with the negative valence of the semantic stereotype of ' $\mathrm{g}$ ' (an evaluative component)

(iii) the acknowledgement that $S$ has negative feelings towards them (an affective component)

Notice that the intended mental state includes a second-order mental state: it is a belief about a speaker's belief, whereas the intended mental state in the case of the more basic (often) informative speech act is just a first-order one, namely, the belief that the hearer belongs in a certain stereotypically characterised group of people. ${ }^{33}$

Finally, it is possible to oppose the act of insulting to another effect that is intended to get achieved by means of it: offending the insulted person, hurting him in his selfesteem or producing those effects in the hearer, in case the insulted person is different from the hearer. From our perspective, offending, as opposed to insulting, is like impressing, namely, a perlocutionary effect, not essential to the act of insulting. More specifically, the speaker may intend to offend the hearer, but, unless he is sensitive to certain attitudes and practices, even if he recognises the speaker's intention, he will remain completely indifferent. (Conversely, if he is sensitive, he might get offended even if the speaker has no intention to offend him and a fortiori no recognition on his part of such an intention could have taken place.) In terms of the previous example, the addressee may grasp the speaker's contempt for Hispanic-Americans, but his selfesteem will remain intact if, for instance, he takes that emotion to be morally reprehensible. Offending seems to be like impressing, in the sense that recognising an intention to offend is not enough for someone to get offended. Accordingly, offending can be taken to be a perlocutionary effect of the speech act of insulting, and, as such, the latter cannot be defined in terms of the former. In other words, insulting cannot be defined in terms of trying to offend someone or as a conventional means to offend

\footnotetext{
32 It is worth taking into account that merely understanding the corresponding slur is not sufficient for this effect to come about, since contempt is not part of the expressive meaning of the term but a pragmatic expressive factor.

${ }^{33}$ Moreover, it is worth pointing out that this first-order belief is a classificatory belief: it involves the classification of a person into a group, which is known to be conventionally linked to certain stereotypical features. But, as stated in the first section of the paper, it does not involve the belief that the person at stake has, as a matter of fact, those features.
} 
someone, since it is not essentially linked to that effect, as much as warning is not essentially linked to frightening or promising is not essentially linked to any specific effect in the hearer, such as making him happy or keeping him calm, perlocutionary effects that may or may not happen as a consequence of a certain promise. ${ }^{34}$

\subsection{Metaphorical Occurrences}

Among the insultive uses, there are some that are characterised by the fact that the speaker lacks any classificatory intention accompanying the derogatory one. In terms of an example, a father who utters,

19) You are a little faggot! Why have you refused to sing?

to rebuke his son for having refused to sing in front of an audience does not have the intention to classify him in a certain stereotypically characterised group of people, namely, the group of male homosexuals, though he does have a derogatory intention aimed at his son as much as the group at stake. From our perspective, the speaker is then actively endorsing the 'faggot' stereotype, which could be described as follows:

'faggot' = COWARDLY, VANE, EFFEMINATE, SENSITIVE, PROMISCUOUS, MORALLY CORRUPT, etc.

It is then an insultive use of the slur or an act with the subkind of insultive illocutionary force we have been focusing on. However, there are two features that allow us to distinguish this kind of use from the previous examples: on the one hand, as we mentioned above, it does not involve an expressively loaded classificatory intention on the speaker's part ${ }^{35}$ and on the other, the use is not a literal but a figurative one. ${ }^{36}$ In accounting for this phenomenon, we will appeal, once again, to the Gricean notion of conversational implicature (Grice 1975). ${ }^{37}$

As is known, Grice understands figurative discourse, paradigmatically, metaphors and ironies, in terms of non-literal contents that are derived from literal ones by means of conversational implicatures. In terms of one of Grice's examples, in using a metaphor like

\section{0) You are the cream in my coffee,}

the speaker intends to communicate that her addressee has some features concerning which he is similar, imaginatively, to the substance at stake, that is, the cream in her

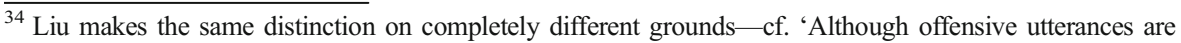
usually conflated with derogatory utterances in the literature, I believe there is a distinction between them; derogation is an illocutionary act, whereas offending is a perlocutionary effect' (Liu 2018: 17).

${ }^{35}$ The fact that the speaker does not have the intention to classify the hearer or a third person in a certain group does not imply that the slur does not have its normal extension; that is why, as we will explain below, the speaker is saying something false, that is, she applies the slur to someone who does not belong in its extension. ${ }^{36}$ The kind of use at stake is what Jeshion (2013b) calls 'a G-extending use', namely, a non-literal use in which the slurring term is applied to an individual the speaker knows not to belong to the target group. It is also an instance of what Croom characterises as 'meaningful and felicitous uses of racial slurs that need not target an individual belonging to the race typically associated with that racial slur' (Croom 2011: 252).

${ }^{37}$ Of course, other theories of figurative language could be applied to the kind of use under study. In this paper, we show how it may be thought to work within a Gricean framework.
} 
coffee. Likewise, we will claim that in uttering (19), the father intends to communicate that his son has some features concerning which he is similar to stereotyped male homosexuals, namely, some of the features of the above-mentioned stereotype, such as COWARDLY, EFFEMINATE, SENSITIVE, etc. Schematically, the father's statement has two contents:

(i) a semantically expressed content $<$ my son is a faggot $>$

(ii) a pragmatically communicated content $<$ my son is cowardly, effeminate, sensitive>

The content in (ii) is derived from the content in (i) by the flouting of the First Maxim of Quality: what the speaker semantically expresses (that his son is a faggot) is literally false, but in so doing he pragmatically communicates or conversationally implicates something he believes to be true (that his son is cowardly, effeminate, sensitive). The father's main intention in uttering (19) is thus to insult his son in an indirect way, namely, not by means of what he semantically expresses (that his son is a faggot) but by means of what he pragmatically communicates (that his son is cowardly, effeminate, sensitive). He insults his son not by including him in the stereotyped group of male homosexuals but by ascribing him the features constitutive of the 'faggot' stereotype with their concomitant negative global value. In the terms of the previous section, in uttering (19), the father intends his son to grasp his contempt by forming the (secondorder) belief that he (the father) believes him (the son) to be (not a stereotyped male homosexual but) cowardly, effeminate and sensitive (together with acknowledging his negative global evaluation and his negative feelings for the people having those features). ${ }^{38}$

\section{Conclusion}

As we said in the introduction, our objective in writing this essay was twofold: (i) explaining the expressive meaning dimension of paradigmatic slurs in terms of a version of stereotype semantics and (ii) analysing their original and most typical insultive uses in terms of a speech act theory. With regard to the first objective, we have suggested that their expressive meaning can be conceived of as a culturally determined evaluative stereotype, namely, a complex concept constituted by an open list of descriptive, thick and purely evaluative ones, with an encoded negative global value. As for the second objective, we have argued that their insultive uses involve a derogatory intention, namely, the kind of communicative intention characteristic of a subkind of speech acts with insultive force. This expressive component is thus pragmatic, that is, not part of their conventional meaning. In sum, we conclude that paradigmatic slurs, semantically linked to evaluative stereotypes with negative valences, are typically used to make insultive speech acts.

\footnotetext{
${ }^{38}$ A further example is provided by an utterance of the following sentence when addressed to a man: 'You are a girl!'. In saying that her addressee is a girl, the speaker is intending not to include him in the stereotyped group of women but to ascribe him the properties of being superficial, vain, dependent, etc., namely, some psychological traits constitutive of the 'girl' stereotype with a concomitant negative global value.
} 


\section{Compliance with Ethical Standards}

Conflict of Interest The authors declare that they have no conflict of interest.

\section{References}

Ashwell, L. (2016). Gendered Slurs. Social Theory and Practice, 42(2), 228-239.

Austin, J. L. (1962). How to do things with words? Oxford: Clarendon Press.

Blackburn, S. (1992). Morality and thick concepts: Through thick and thin. Proceedings of the Aristotelian Society, Supplementary, 66, 285-299.

Burge, T. (1979). "Individualism and the mental". Midwest Studies in Philosophy, 4 (1), 73-122.

Camp, E. (2013). Slurring perspectives. Analytic Philosophy, 54(3), 330-349.

Caso, R., \& Lo Guercio, N. (2016). What bigots do say: A reply to DiFranco. Thought: A Journal of Philosophy, 5(4), 265-274.

Croom, A. M. (2011). Slurs. Language Sciences, 33, 343-358.

Croom, A. M. (2013). How to do things with slurs: Studies in the way of derogatory words. Language and Communication, 33, 177-204.

Croom, A. M. (2014). The semantics of slurs: A refutation of pure expressivism. Language Sciences, 41, 227242.

Croom, A. M. (2015). The semantics of slurs: A refutation of coreferentialism. Ampersand, 2, 30-38.

Davidson, D. (1980). Essays on Actions and Events. Oxford: Oxford University Press.

Díaz Legaspe, J. (2018). Normalizing slurs and out-group slurs: The case of referential restriction. Analytic Philosophy, 59(2), 1-22.

Díaz Legaspe, J., Liu, Ch. \& Stainton, R. (2019). "Slurs and register: A case study in meaning pluralism”. (in The Selected Works of Robert Stainton. The University of Western Ontario, available at https://works. bepress.com/robertstainton/140/ ).

Gibbard, A. (1992). Morality and thick concepts: Thick concepts and warrant for feelings. Proceedings of the Aristotelian Society, Supplementary, 66, 267-283.

Grice, H. P. (1957). Meaning. Philosophical review, 66, (3) 377-388. In H. P. Grice (Ed.), Reprinted as ch. 14 of Studies in the way of words (pp. 213-233). Cambridge: Harvard University Press.

Grice, H. P. (1975). Logic and conversation. In P. Cole \& J. Morgan (Eds.), Syntax and Semantics 3 (pp. $22-$ 40). Cambridge: Academic Press. Reprinted as ch. 2 of Grice 1989.

Gutzmann, D. (2015). Use-conditional meaning. Studies in multidimensional semantics. Oxford: Oxford University Press.

Hom, C. (2008). The semantics of racial epithets. The Journal of Philosophy, 105, 416-440.

Hom, C. (2010). Pejoratives. Philosophy Compass, 5(2), 164-185.

Hom, C. (2012). A puzzle about pejoratives. Philosophical Studies, 159(3), 383-405.

Jeshion, R. (2013a). Slurs and stereotypes. Analytic Philosophy, 54, 314-325.

Jeshion, R. (2013b). Expressivism and the offensiveness of slurs. Philosophical Perspectives, 27, 231-259.

Kaplan, D. (1999). The meaning of ouch and oops: Explorations in the theory of meaning as use. (MS, Los Angeles: University of California.)

Kirchin, S. (2017). Thick evaluation. Oxford: Oxford University Press.

Liu, Ch. (2018). "Slurs as illocutionary force indicators". (MS, University of Western Ontario).

McCready, E. (2010). Varieties of conventional implicature. Semantics and Pragmatics, 3(8), 1-57.

McDowell, J. (1981). Non-cognitivism and rule-following. In S. Holtzman \& C. Leich (Eds.), Wittgenstein: To Follow a Rule (pp. 141-162). London: Routledge and Kegan Paul.

Nunberg, G. (2018). The social life of slurs. In D. Fogal, D. Harris, \& M. Moss (Eds.), New Work on Speech Acts. Oxford: Oxford University Press.

Potts, C. (2003). Expressive content as conventional implicature. In Makoto K, Shigeto K (Eds.) Proceedings of the North East Linguistic Society 33 (pp. 303-322). GLSA, Amherst.

Potts, C. (2005). The logic of conventional implicatures. Oxford: Oxford University Press.

Predelli, S. (2013). Meaning without truth. Oxford: Oxford University Press.

Putnam, H. (1970). Is semantics possible?. Reprinted in Mind, Language and Reality. Philosophical Papers vol. 2. Cambridge: Cambridge University Press, 1975.

Putnam, H. (1975). The meaning of 'meaning'. Reprinted in Mind, Language and Reality. Philosophical Papers vol. 2. Cambridge: Cambridge University Press, 1975. 
Saka, P. (2007). Hate speech. In How to think about meaning (pp. 121-154). Dordrecht: Springer.

Schlenker, P. (2007). Expressive presuppositions. Theoretical Linguistics, 33(2), 237-245.

Searle, J. (1969). Speech acts. An essay in the philosophy of language. Cambridge: Cambridge University Press.

Searle, J. (1975). A taxonomy of illocutionary acts. In Gunderson, K. (Ed.), Language, mind and knowledge (pp. 344-369). Minneapolis: University of Minnesota Press. Reprinted in Searle, J. (1979). Expression and meaning. Cambridge: Cambridge University Press.

Sendlmeier, W., Steffen, I., \& Bartels, A. (2016). Pejorative prosody. In R. Finkbeiner, J. Meibauer, \& H. Wiese (Eds.), Pejoration (pp. 21-40). Amsterdam-Philadelphia: John Benjamins Publishing Company.

Strawson, P. (1964). Intention and convention in speech acts. The Philosophical Review, 73(4), 439-460.

Technau, B. (2016). The meaning and use of slurs. An account based on empirical data. In R. Finkbeiner, J. Meibauer, \& H. Wiese (Eds.), Pejoration (pp. 187-218). AmsterdamPhiladelphia: John Benjamins publishing company.

Technau, B. (2018). Going beyond hate speech: The pragmatics of ethnic slur terms. Lodz Papers in Pragmatics, 14(1), 25-43.

Tenchini, M. P., \& Frigerio, A. (2016). A multi-act perspective on slurs. In R. Finkbeiner, J. Meibauer, \& H. Wiese (Eds.), Pejoration (pp. 167-186). Amsterdam-Philadelphia: John Benjamins publishing company.

Väyrynen, P. (2011). Thick concepts and variability. Philosophers' Imprint, 11(1), 1-17.

Whiting, D. (2013). It's not what you said, It's the way you said it: Slurs and conventional Implicature. Analytic Philosophy, 54(3), 364-377.

Williams, B. (1985). Ethics and the limits of philosophy. Cambridge: Harvard University Press.

Williamson, T. (2009). Reference, inference, and the semantics of pejoratives. In J. Almog \& P. Leonardi (Eds.), The Philosophy of David Kaplan (pp. 137-158). Oxford: Oxford University press.

Wittgenstein, L. (1953). Philosophical Investigations (the German text, with an English translation by G. E. N. Anscombe, P. M. S. Hacker \& Joachim Schulte, revised 14th. Edition by P. M. S. Hacker \& Joachim Schulte, Oxford: Blackwell, 2009).

Publisher's Note Springer Nature remains neutral with regard to jurisdictional claims in published maps and institutional affiliations. 